\title{
Immunosuppressive and Hematopoiesis-Supporting Properties of Stromal Cells at Low Oxygen
}

\author{
Elena R Andreeva*, Irina V Andrianova, Polina I Bobyleva, Ludmila B Buravkova \\ Cell Physiology lab, Institute of BioMedical Problems, Russian Academy of Sciences, Moscow, Russia \\ *Corresponding author: andreeva_er@mail.ru \\ Received January 11, 2013; Revised January 31, 2013; Accepted February 28, 2013
}

\begin{abstract}
In adults, low differentiated stromal cells like fibroblasts, multipotent mesenchymal stromal cells, reticular cells etc. are important integrative components of tissue homeostasis and regeneration. The purpose of this study was to compare immunomodulatory activity and hematopoiesis-supportive capacity of two human stromal cell types: fetal fibroblasts (fFBs) and multipotent mesenchymal stromal cells (MMSCs) under different oxygen tension (20\% vs. 5\%). Surface immunophenotyping by flow cytometry revealed that MMSCs and fFBs were CD90, CD105, HLA-ABC positive and CD34, CD45, HLA-DR negative regardless of the $\mathrm{O}_{2}$ concentration. The percentage of Tcells was relatively unchanged after 72 hours co-culture with stromal cells; the proportion of B- and NK-cells was

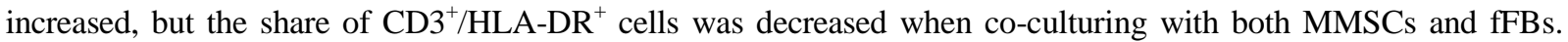
This reduction was statistically significant at $5 \% \mathrm{O}_{2}$ in comparison with $20 \% \mathrm{O}_{2}(\mathrm{p}<0.05)$. CD $3^{+} / \mathrm{CD}^{2} 5^{+}$cells decreased after co-culture with both stromal cells in $20 \% \mathrm{O}_{2}$. This effect was revealed only for MMSC at $5 \% \mathrm{O}_{2}$. After 72 hours in co-culture with MMSCs, mononuclear cells from umbilical cord blood (CBMCs) maintained the same number of colony forming units (CFU) as compared with the initial CBMC suspension. The number of CFU was $30 \%$ higher at $5 \% \mathrm{O}_{2}$ than in $20 \% \mathrm{O}_{2}(\mathrm{p}<0.05)$. The CFU number in CBMCs after co-culture with fFBs decreased and a stimulatory effect of low oxygen was not observed. CBMCs that were adhered to MMSCs formed colonies of undifferentiated progenitors after 2 weeks of co-culture both at $20 \%$ and $5 \% \mathrm{O}_{2}$. Colonies were not found on fFBs. The immunomodulatory potency and the hematopoiesis-supportive capacity of stromal cells can vary depending on their tissue origin and may be modified by the partial pressure of oxygen.
\end{abstract}

Keywords: human multipotent mesenchymal stromal cells from adipose tissue, human fetal fibroblasts, peripheral blood mononuclear cells, mononuclear cells from umbilical cord blood, coculture, immunosuppression, hematopoiesis, low oxygen tension

\section{Introduction}

Stromal cells of mesenchymal origin such as fibroblasts (FBs) and multipotent mesenchymal stromal cells (MMSCs) play an important role of the physiological and regenerative microenvironment modifying certain properties of other cell types. MMSCs have generated a great deal of excitement and promise as a potential source of cells for cell-based therapeutic strategies due to their immunosuppressive properties and immunotolerance $[1,2,3]$. Recent studies have demonstrated that FBs can be functionally equivalent to MMSCs to some extent [4,5]. In addition, stromal cells constitute the basic structural and functional component of the highly specialized hematopoietic tissue niche where the cell-cell interaction is controlled by microenvironment factors, with partial pressure of oxygen being the leading one. Up to now, a large amount of data has been gathered on how changes in $\mathrm{O}_{2}$ levels modulate cell properties, with regard to MMSCs in particular [6,7]), which may affect their relationship with other cells. In the present paper we have analyzed the immunomodulating and hematopoiesis-supporting properties of two types of stromal cells: human MMSCs from adipose tissue and human fetal FBs. In addition, the effects of oxygen level on the interaction of human stromal cells and differentiated human MMSCs from adipose tissue and human fetal FBs is also investigated. Besides, the effects of oxygen level on the interaction of human stromal cells and differentiated and progenitor blood mononuclear cells was studied in vitro.

\section{Materials and Methods}

\subsection{Cell Culture}

Multipotent mesenchymal stromal cells (MMSCs) were isolated from the stromal-vascular fraction of human adipose tissue as previously described [8] with some modifications [7]. Briefly, adipose tissue was obtained from elective liposuction procedures under local anesthesia from healthy patients after informed consent was obtained in the multidisciplinary clinic "Souz" (Moscow, Russia) and treated with $0.075 \%$ collagenase IA (Sigma-Aldrich, USA). After washing, cells were resuspended in DMEM low glucose (MP Biomedicals, USA), supplemented with $10 \%$ FBS (Hyclone, USA), $250 \mu \mathrm{g} / \mathrm{ml}$ amphotericin, $5 \mu \mathrm{g} / \mathrm{ml}$ streptomycin, 
5U/ml penicillin, and 2mM glutamine (MP Biomedicals, USA).

Human fetal fibroblasts (fFBs) were kindly gifted by Prof. B.K.Gavriluk (Institute of Theoretic and Experimental Biophysics, Pushchino, Russia). Cells of 2-8 passages were cultured in the same culture medium and gaseous conditions as mentioned above for MMSCs. Mononuclear cells from peripheral blood (PBMCs) of healthy volunteers were isolated by Ficoll-Histopaque gradient ( $\rho 1,077)$, (Sigma, США) according to standard protocol.

Cryopreserved samples of mononuclear cells from umbilical cord blood (CBMCs) were obtained from the Stem cell bank Cryocenter (Moscow, Russia).

\subsection{Permanent Expansion of Stromal Cells under Low Oxygen}

MMSCs after isolation and fFBs after thawing were divided into two parts. The first was further expanded at $5 \% \mathrm{CO}_{2}$ and $95 \%$ air $\left(20 \% \mathrm{O}_{2}\right)$ in a $\mathrm{CO}_{2}$-incubator (Sanyo, Japan) (normoxia); the other at $5 \% \mathrm{O}_{2}, 5 \% \mathrm{CO}_{2}, 90 \% \mathrm{~N}_{2}$ (hypoxia) in a multigas incubator (Sanyo, Japan). After reaching $70-80 \%$ confluence, cells were sub-cultured and 2-4 passages of MMSCs and 5-10 passages of fFBs were used in experiments.

\subsection{Co-culture of PBMCs and Stromal Cells}

PBMCs were activated with PHA $(10 \mu \mathrm{g} / \mathrm{ml})$ and were seeded without stromal cells (monoculture) or on preformed layers of normoxic and hypoxic MMSCs and fFBs (70-80\% confluence) at a ratio of 10:1 PBMCs/stroma, and not less than $1 \times 10^{6} \mathrm{PBMCs} / \mathrm{ml}$. Cells were co-cultured in RPMI 1640 medium (MP Biomedicals, USA), supplemented with $10 \%$ inactivated FBS (Hyclone, USA), $250 \mu \mathrm{g} / \mathrm{ml}$ amphotericin, $5 \mu \mathrm{g} / \mathrm{ml}$ streptomycin, $5 \mathrm{U} / \mathrm{ml}$ penicillin, and $2 \mathrm{mM}$ glutamine (MP Biomedicals, USA) for 72 hours in normoxia $\left(20 \% \mathrm{O}_{2}\right)$ and hypoxia $\left(5 \% \mathrm{O}_{2}\right)$. Then, PBMCs were harvested by rinsing with PBS and stained for FACS analysis as described below.

\subsection{Co-culture of CBMCs and Stromal Cells}

$1 \times 10^{6} / \mathrm{ml}$ of CBMCs were added to preformed stromal layers and co-cultured for 72 hours in the same medium as PBMCs in normoxic and hypoxic conditions. Then, unattached CBMCs were carefully washed out and the suspension of CBMCs was examined for CFU-activity in colony-forming cell assay. Stromal cells with attached CBMCs were further cultured up to 14 days and then the formation of undifferentiated precursor colonies on stromal feeders was assessed after Crystal violet staining.

Cell-cell interactions were monitored using Nikon Eclipse Ti-U microscope equipped with a Color Digital Camera DS-Ri1. Images were saved and later processed with NIS-Elements Auto Research software (Nikon Instruments, Japan).

\subsection{FACS Analysis}

For immunophenotyping of stromal cells, antibodies against the following antigens were used: CD34, CD45, CD54, CD90, CD105, CD106, CD117(c-kit), HLA-ABC, HLA-DR and vimentin.
To identify lymphocyte types, antibodies against CD3+ ( $\mathrm{T}$ cells), CD3-/CD19+ (B cells), CD3-/16+/56+ (NK cells) were applied. Activated lymphocytes were recognized with anti-HLA-DR and anti-CD25 antibodies. All antibodies were directly conjugated to FITC or PE (all BD Biosciences, USA).

Fluorescence was measured with Epics XL cytofluorimeter using the manufacturer's System II software for acquisition, analysis and for the creation of figures (Beckman Coulter, USA).

\subsection{Colony-forming Cell (CFC) Assay}

Freshly thawed CBMCs and cells after 72 hours coculture with stromal cells $\left(50 \times 10^{3}\right.$ cells $\left./ \mathrm{ml}\right)$ were cultured in methylcellulose-based medium MetoCult H4534 (StemCells, USA) according to the manufacturer's protocol at $20 \%$ and $5 \% \mathrm{O}_{2}$. After 14 days, the number of CFCs was calculated.

\subsection{Statistical Analysis}

All data were derived from at least three independent experiments. Data are presented as mean \pm standard error of the mean $(\mathrm{M} \pm \mathrm{m})$. Statistical comparisons were performed using the Student's two-tailed $t$-test (unpaired/paired) in an Excel program. A P-value less than 0.05 was considered statistically significant.

\section{Results}

\subsection{Immunophenotype of MMSCs vs. fFBs}

Adipose tissue-derived MMSCs used in this work met the criteria for immunophenotypic identification of MMSCs [9] (Table 1). The analysis of the fFBs phenotype with the same antibody panel showed the virtual identity of the CD profile (Table 1), although fFBs and MMSCs were isolated from different tissues. The vast majority of MMSCs and fFBs had MMSC markers CD90 and CD105. All cells were positive on class-I major histocompatibility complex (HLA-ABC) antigen and had no class-II antigen (HLA-DR); they also contained vimentin, an intermediate filament common to cells of mesenchymal origin. Cells with the hematopoietic cell markers (CD34, CD45, HLADR) were few if any. It should be noted that reduced oxygen (5\% vs. ambient $20 \%$ ) in culture medium had no effect on the stromal cell immunoprofile.

Table 1. Expression of mesenchymal stem cell/progenitor markers in stromal cells

\begin{tabular}{|c|c|c|}
\hline \multirow{2}{*}{ CD marker } & MMSCs & fFBs \\
\cline { 2 - 3 } & Positively stained cells, \% (min $\div$ max $)$ \\
\hline CD90 & $88.9 \div 98.1$ & $93.3 \div 97.5$ \\
\hline CD105 & $95.9 .3 \div 97.6$ & $99.9 \div 100.0$ \\
\hline CD54 & $34.0 \div 70.2$ & $24.9 \div 27.8$ \\
\hline CD106 & $11.9 \div 36.80$ & $99.9 \div 100.0$ \\
\hline HLA-ABC & $98.6 \div 99.5$ & $99.6 \div 99.7$ \\
\hline vimentin & 100.0 & 100.0 \\
\hline CD34 & $1.7 \div 2.0$ & $0 \div 2.6$ \\
\hline CD45 & 0.0 & 0.0 \\
\hline CD117(c-kit) & $1.6 \div 2.7$ & 0.0 \\
\hline HLA-DR & 0.0 & 0.0 \\
\hline
\end{tabular}

Min and max values in three independent experiments are shown 


\subsection{Immunomodulating Properties}

Human lymphocyte types and activation in co-culture with stromal cells. The distribution of human lymphocyte types (T, B and NK cells) and T cell activation were analyzed after 72 hours of co-culture of PHA-activated PBMCs with stromal cells. All effects were normalized on respective values for $\mathrm{PHA}-\mathrm{PBMCs}$ in monoculture and presented as a fold changes (Table 2). Co-cultures with stromal cells either had no affect (in the case of fFBs) or caused a slight reduction of the T-cell share (in case of MMSCs). The percentage of B cells increased and was more pronounced in the presence of MMSCs. The proportion of NK cells increased also; in NK case this effect was more significant in co-culture with fFBs. The increase in B cells was more and in NK less pronounced at $5 \% \mathrm{O}_{2}$ as compared with the $20 \% \mathrm{O}_{2}$, regardless of the stromal cell type. The activation of $\mathrm{T}$ cells was suppressed both in MMSC/PBMC and fFB/PBMC co-cultures. In case of $\mathrm{CD} 3+/ \mathrm{HLA}-\mathrm{DR}+$ cells, the drop was more significant at $5 \% \mathrm{O}_{2}$. The number of CD3+/CD25+ cells was similarly diminished in MMSC/PBMCs at $20 \%$ and $5 \% \mathrm{O}_{2}$, and this effect was more pronounced (up to $40 \%$ ) than in fFB/PBMCs. The decrease in CD3+/CD25+cells was not revealed after $\mathrm{fFB} / \mathrm{MCs}$ co-culture under hypoxia.

Table 2. Lymphocyte types and activation after co-culture with stromal cells under different $\mathrm{O}_{2}$ conditions

\begin{tabular}{|c|c|c|c|c|}
\hline \multirow{4}{*}{ Fold change from the values for PHA-activated PBMCs } \\
\hline & \multicolumn{2}{|c|}{$20 \% \mathrm{O}_{2}$} & \multicolumn{2}{c|}{$5 \% \mathrm{O}_{2}$} \\
\cline { 2 - 5 } & MMSCs & fFBs & MMSCs & fFBs \\
\hline $\begin{array}{c}\text { T cells } \\
(\mathrm{CD} 3+/ \mathrm{CD} 19-)\end{array}$ & $0.9 \pm 0.1$ & $1.0 \pm 0.1$ & $0.9 \pm 0.1$ & $1.0 \pm 0.1$ \\
\hline $\begin{array}{c}\text { B cells } \\
(\mathrm{CD} 3-/ C D 19+)\end{array}$ & $1.5 \pm 0.3$ & $1.3 \pm 0.3$ & $1.8 \pm 0.3$ & $1.4 \pm 0.6$ \\
\hline $\begin{array}{c}\text { EK (CD3- } \\
/ \mathrm{CD} 16+/ C D 56+)\end{array}$ & $1.9 \pm 0.5$ & $2.2 \pm 0.5$ & $1.8 \pm 0.3$ & $2.0 \pm 0.3$ \\
\hline $\begin{array}{c}\text { T cells } \\
(\mathrm{CD} 3+/ \mathrm{HLA}- \\
\text { DR+) }\end{array}$ & $0.9 \pm 0.2$ & $0.9 \pm 0.1$ & $0.7 \pm 0.2^{*}$ & $0.8 \pm 0.1 *$ \\
\hline $\begin{array}{c}\text { T cells } \\
(\mathrm{CD} 3+/ \mathrm{CD} 25+)\end{array}$ & $0.6 \pm 0.1$ & $0.8 \pm 0.1$ & $0.6 \pm 0.1$ & $1.0 \pm 0.1$ \\
\hline
\end{tabular}

$*$ Significant differences from values at $20 \% \mathrm{O}_{2}(\mathrm{p}<0.05)$

Therefore, co-culture with stromal cells provoked the alteration in PHA-activated lymphocyte types as well as T cell activation. In the presence of fFBs, the percentage of NK cells was more and B cells less in comparison with same types in MMSC/MC co-culture. MMSCs and fFBs equally suppressed the population of HLA-DR-positive lymphocytes; however, the presence of fFBs had a little $\left(20 \% \mathrm{O}_{2}\right)$ or no $\left(5 \% \mathrm{O}_{2}\right)$ effect on $\mathrm{CD} 25$-expressing cells.

\subsection{Hematopoiesis-supporting Properties}

Colony forming cell (CFC) evaluation. To characterize the ability of stromal cells to maintain hematopoietic progenitors, in vitro colony forming activity was assessed in the initial cord blood MCs (CBMCs) and in the nonattached fraction of these cells after 72 hours of co-culture with MMSCs and fFBs. Initial CBMCs formed 25\% more colonies at $5 \% \mathrm{O}_{2}$ (Figure 1 (1)). Following 72 hours of co-culture with MMSCs, CBMCs retained the CFpotential, which was again more pronounced after coculture at $5 \% \mathrm{O}_{2}$ (Figure 1 (2)). The CF-activity was attenuated in CBMCs after co-culture with fFBs. This effect was particularly evident after hypoxic co-culture (Figure 1 (3)).

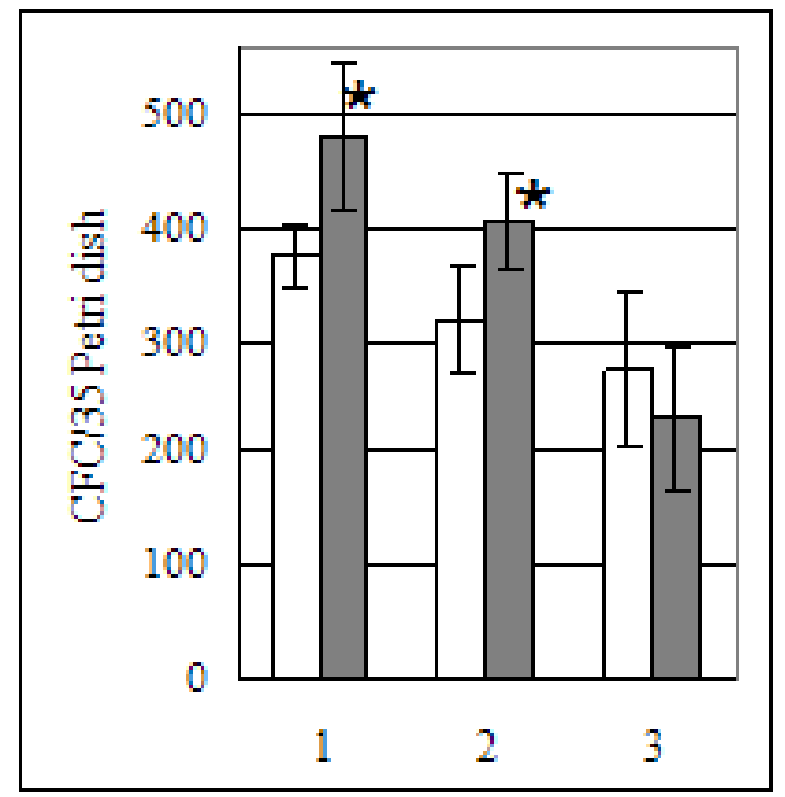

1. Initial CBMCs; 2. CBMCs after 72 hours of co-culture with MMSCs 3. CBMCs after 72 hours of co-culture with fFBs. White bar-co-culture at $20 \% \mathrm{O} 2$; Grey bar - co-culture at $5 \% \mathrm{O} 2 ; *$ - $\mathrm{P}<0.05$ compared with fFBs

Figure 1. Colony- formation efficiency of CBMCs in MetoCult H4534

Formation of progenitor colonies on stromal layers. The part of CBMCs remained adhered to the stromal cells after 72 hours of co-culture (Figure 2 a-d). During the ensuing cultivation, these cells were able to form colonies of undifferentiated progenitors. 10 days later, these colonies were found on MMSCs and were not detected on fFBs (Figure $3 \mathrm{a}-\mathrm{d}$ ), regardless of the $\mathrm{O}_{2}$ concentration in the medium.

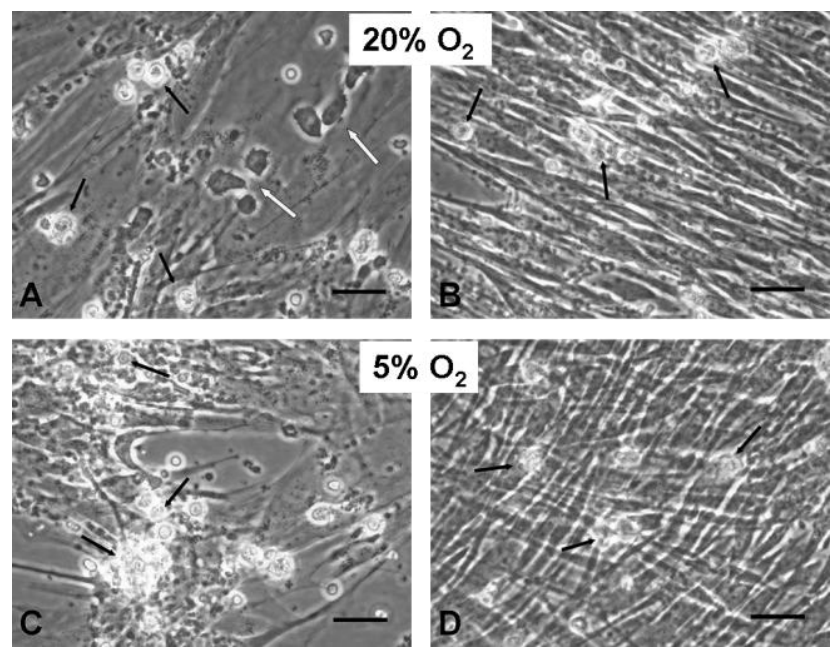

a, b-CBMCs/MMSCs; c,d - CBMCs/fFBs; a, c-20\% O2, b,d - $5 \% \mathrm{O} 2$. Adhered CBMCs look as shiny rounded cells (marked with black arrows), some of them are well spreaded on stromal cell's surface (white arrows), phase contrast, bars $=50 \mathrm{um}$

Figure 2. CBMCs adhesion on stromal cells after 72 hours of co-colture

To sum up, umbilical cord blood hematopoietic progenitors retained the ability to form colonies in the semi-solid medium after co-culture with stromal cells. The CFU-activity after co-culture with fFBs was noticeably 
less when compared with initial CBMCs and co-cultured with MMSCs. CBMCs adhered to the MMSCs formed colonies of undifferentiated progenitors both at $20 \%$ and $5 \% \mathrm{O}_{2}$; no colony was detected on the fFBs monolayer.
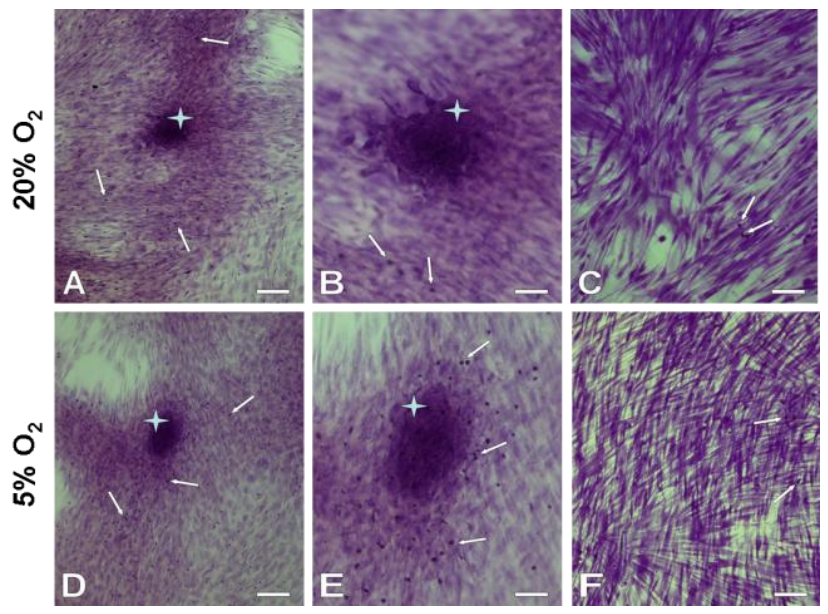

a, b, d, e - CBMCs/MMSCs; c,f - CBMCs/fFBs; a-c - 20\% $\mathrm{O}_{2}$, d-f - $5 \%$ $\mathrm{O}_{2}$. CBMCs were co-cultured with stromal cells for 72 hours and then all floating CBMCs were removed. After 14 days from the start of experiments, undifferentiated precursor colonies were revealed on stromal feeders. White asterisks - precursor's colonies, Black arrows single CB-born cells. Bright field, Crystal violet staining, bars $=100 \mu \mathrm{m}$ $(\mathrm{a}, \mathrm{d})$, bars $=50 \mu \mathrm{m}(\mathrm{b}, \mathrm{c}, \mathrm{e}, \mathrm{f})$

Figure 3. Stromal monolayers after 14 days of co-culture with CBMCs

\section{Discussion}

In the present paper we have compared some aspects of immunomodulating and hematopoiesis-supporting activity of two types of human stromal cells: adipose tissue derived MMSCs and fetal FBs. These properties appeared to be different in MMSCs and fFBs to some extent despite the fact that both cell types are low differentiated cells of mesenchymal origin.

The histogenetic relationship of FBs and MMSCs is still not fully elucidated. Stromal cells currently defined as MSCs were isolated by Friedenstein et al. [9] from bone marrow and termed "fibroblast-like cells". The main features of these cells were the ability to adhere to substrate, to form colonies of progenitor cells (CFU-F) and to differentiate both in vivo and in vitro into other types of mesenchymal cells (adipocytes, osteoblasts, and chondroblasts). Later on, these cells were termed multipotent mesenchymal stem (stromal) cells (MMSCs) and much effort was spent to establish the "degree of kinship" between FBs and MMSCs [10,11]. Today, MMSCs and FBs can be isolated from a large variety of tissues $[12,13]$. It was found that, despite the diversity of sources, it is very difficult to distinguish MMSCs from FBs using the morphologic and immunophenotype criteria. All surface antigens used to identify MMSCs are also present on FBs $[14,15]$. This finding is supported by our results on similar immunoprofile of human adipose tissuederived MMSCs and human fetal FBs. The capacity for multilineage differentiation - a key MMSCs property, and immunosuppression are regarded as specialized functions arising from their low differentiated multipotent nature $[14,16]$. However, the ontogenetic studies [17,18] provided evidence suggesting that FBs are one of the most primitive cells of adult tissues. This gives a reason to suppose that FBs can share the same MMSC multipotent properties, particularly with regard to effects on the immune cells and hematopoietic progenitors' maintenance.

MMSC immunomodulation activity now is well recognized. Thus, there is a clear demonstration that coculture with MMSCs reduces allogenic T-lymphocyte proliferation, induces T-cell anergy and apoptosis, modulates cytokines production by immunocompetent cells, and inhibits T-cell activation and also maturation of dendritic cells. This immunomodulation is antigennonspecific and mediated by several soluble factors such as TGF- $\beta, \mathrm{PGE}_{2}$ and tryptophan metabolites [1,2,3]. Data on FBs are less consistent. It has long been shown that these cells can take on the role of alternative antigenpresenting cells activating or suppressing T-lymphocytes $[4,19]$ and mediating indirect anti-proliferating effects [20]. Still, there exists an opinion that stromal cells like FBs do not possess the immunosuppressive activity [14]. Nonetheless, it can be surmised that the immunomodulation properties are common to the stromal cells.

We have revealed an increase in NK and $\mathrm{B}$ cell percentages in suspensions of PHA-activated PBMCs after co-culture with both stromal cells. However, the increase in NK was more substantial in the presence of fFBs, whereas the increase of B cell proportion was more pronounced with MMSCs. In addition, the pattern of Tcell suppression was also different. The percentage of HLA-DR-positive cells was equally reduced after coculture with MMSCs and fFBs. However, the fFBs impact on CD25-expression was weak $\left(20 \% \mathrm{O}_{2}\right)$ or none $\left(5 \% \mathrm{O}_{2}\right)$. That is, MMSCs suppressed expression T cells with both early (CD25) and late (HLA-DR) activation markers in normoxic and hypoxic conditions. In co-culture with fFBs, $\mathrm{T}$ cells with both activation markers were inhibited at $20 \%$ $\mathrm{O}_{2}$ and of late HLA-DR only at $5 \% \mathrm{O}_{2}$.

The case of the fluctuation in lymphocyte types during co-culture with stromal cells has not yet been fully resolved. It is well known that activated $\mathrm{T}$ cells adhere to the stromal layer forming the high specific cell-to-cell contacts [21,22] and are even able to migrate into the space beneath the cells and back onto the stroma surface [21]. Recently we have shown that, in contrast to inactivated immune cells, PHA-activated PBMCs have effectively adhered to MMSCs and spread on their surface, and were able to transmigrate under stromal cells. This interaction involves at least one of the highly specific ligand-receptor paths mediated by ICAM-1 [23]. It can be assumed that the elevation of B and NK proportions in unattached PBMCs can be associated with the predominant adhesion of activated $\mathrm{T}$ cells. In addition, our data on the $\mathrm{T}$ cells' suppression after co-culture with stromal cells may be also caused by peculiarities of activated lymphocytes' «interplay» with MMSCs and fFBs.

At present, the use of stromal cells as feeders for hematopoietic cell expansion ex vivo is the routine cell culture practice [24,25]. Initially, the feeder for hematopoietic cells consisted of a total population of adhesive marrow cells including stromal, endothelial and reticular cells, fibroblasts, pre-adipocytes, etc. This system was called "Dexter's culture" [24]. Afterwards, HSC expansion on purified feeder cells such as FBs [26], stromal cells harvested from Dexter's cultures MS-5 
[27,28] and MS-K [27] came into use; finally, MMSCs became of the primary choice $[29,30,31,32])$.

In the present study, we demonstrated that hematopoietic cells from human cord blood retain the CFC-activity in semi-solid medium after co-culture with stromal progenitors. We assayed the ability of CBMCs to form the colonies of progenitor cells on the stromal monolayers (MMSCs and fFBs) at different $\mathrm{O}_{2}$ concentrations in culture medium. It was found that the number of CFCs among CBMCs co-cultured with MMSCs was slightly less than among initial CBMCs. Progenitor colonies were formed on the MMSC monolayer both at $20 \%$ and $5 \% \mathrm{O}_{2}$. The CFC number after co-culture with fFBs was noticeably less in comparison with initial CBMCs and those co-cultured with MMSCs; no colony was detected on the fFBs monolayer. These data are in agreement with the earlier observations of Wagner et al. [30] who demonstrated the enhanced CD34 ${ }^{+}$ cells hematopoiesis-supportive capacity of human bone marrow MMSCs than FB HS68 cell line. Today, most protocols for ex vivo expansion of hematopoietic cells preferentially employ MMSCs. However, comparison of the data from different studies is very complicated. This is due in part to differences in the experimental design. For instance, some laboratories irradiate a stromal supporting layer $[26,30,32]$. In this study we used intact premonolayer stromal cells as a feeder, as in [29]. Naturally, the profile of secreted biologically active substances will vary with the technique of supporting layer preparation. Besides, stromal and hematopoietic cells are co-cultured in a huge variety of media (i.e. with and without cytokines, chemokines and growth factors). The standard cocktail of stem cell growth factor (SCF), FL-3 ligand (FL3) and thrombopoietin (TPO) in addition to stroma feeder raises the effectiveness of hematopoietic cell expansion significantly [29,33]. Nevertheless, these expensive growth media are not economical for clinical needs; therefore, preference can be given to intrinsic biologically active mediators produced by stromal cells. Using the conventional culture medium for stromal cell expansion (low glucose DMEM with standard supplements) in a 14day experiment, we observed a better potential of MMSCs but not fFBs for maintaining hematopoietic cells from human umbilical cord blood. It is possible that the addition of growth factors or the extension of the experiment duration could help to reveal hematopoiesissupportive potential of fFBs. It can be assumed that hematopoiesis-inducing capacities of stromal cells can vary in extent and time of realization and depend on microenvironmental parameters.

\section{Conclusions}

In conclusion, the stromal cells from different sources like human MMSCs from the stromal-vascular fraction of adipose tissue and fetal FBs have similar but not identical properties which can be considered a manifestation of their stromal and immunosuppressive potential. In addition, the partial oxygen pressure is an important physical factor that also modifies the results of cell-cell interactions and, therefore, should be taken into account when defining methodical approaches with regard to the use of stromal cells for the needs of regenerative medicine.

\section{List of Abbreviations}

MMSCs: multipotent mesenchymal stromal cells; fFBs: fetal fibroblasts; PBMCs: mononuclear cells from peripheral blood; CBMCs: mononuclear cells from umbilical cord blood; FCS: fetal calf serum; CFC, CFU: colony forming cell, colony forming unit; FACS: fluorescent activated cell sorting.

\section{Competing Interests}

The authors declare they have no competing interests.

\section{Acknowledgements}

This study was supported in part by a grant from the Basic Research Program \#7 of Presidium of the Russian Academy of Science. We sincerely thank Dr. Olga V Grigorieva for assistance with co-culture experiments.

\section{References}

[1] Jones, B.J. and McTaggart, S.J., Immunosuppression by mesenchymal stromal cells: from culture to clinic, Exp Hematol, 36(6): 733-741, 2008.

[2] Buravkova, L.B. and Andreeva, E.R., Interaction of human multipotential mesenchymal stromal and immune cells, Human Physiology, 36(5): 110-120, 2010.

[3] Chen, P.M., Yen, M.L., Liu, K.J., Sytwum H.K. and Yenm B.L., Immunomodulatory properties of human adult and fetal multipotent mesenchymal stem cells, J Biomed Sci., 18(1): 49, 2011.

[4] Sarkhosh, K., Tredget, E.E., Karami, A., Uludag, H., Iwashina, T., Kilani, R.T. and Ghahary, A., Immune cell proliferation is suppressed by the interferon-gamma-induced indoleamine 2,3dioxygenase expression of fibroblasts populated in collagen gel (FPCG), J Cell Biochem,. 90(1): 206-217, 2003.

[5] Haniffa, M.A., Wang, X.N., Holtick, U., Rae, M., Isaacs, J.D., Dickinson, A.M., Hilken, C.M. and Collin, M.P., Adult human fibroblasts are potent immunoregulatory cells and functionally equivalent to mesenchymal stem cells, J Immunol., 179(3): 15951604, 2007.

[6] Fehrer, C., Brunauer, R., Laschober, G., Unterluggauer, H., Reitinger, S., Kloss, F., Gully, C., Gassner, R. and Lepperdinger, G., Reduced oxygen tension attenuates differentiation capacity of human mesenchymal stem cells and prolongs their lifespan, Aging Cell. 6(6): 745-757, 2007.

[7] Buravkova, L.B., Grinakovskaya, O.S., Andreeva, E.P., Zhambalova, A.P. and Kozionova, M.P., Characteristics of human lipoaspirate-isolated mesenchymal stromal cells cultivated under a lower oxygen tension, Cell and Tissue Biology., 3(1): 23-28, 2009.

[8] Zuk, P., Zhu, M., Ashjian, P., De Ugarte, D.A., Huang, J.I., Mizuno, H., Alfonso, Z.C., Fraser, J.K., Benhaim, P. and Hedrick, M.H., Human adipose tissue is a source of multipotent stem cell, Mol Biol Cell., 13(12): 4279-4295, 2002.

[9] Friedenstein, A.J., Gorskaja, J.F. Sep Exp Hematol 1976, 4:267274Kulagina, N.N., Fibroblast precursors in normal and irradiated mouse hematopoietic organs, Exp Hematol., 4(5): 267-274, 1976.

[10] Ishii, M., Koike, C., Igarashi, A., Yamanaka, K., Pan, H., Higashi, Y., Kawaguchi, H., Sugiyama, M., Kamata, N., Iwata, T., Matsubara, T., Nakamura, K., Kurihara, H., Tsuji, K. and Kato., Y., Molecular markers distinguish bone marrow mesenchymal stem cells from fibroblasts, Biochemical and Biophysical Research Communications, 332(1): 297-303, 2005.

[11] Bae, S., Ahn, J.H., Park, C.W., Son, H.K., Kim, K.S., Lim, N.K., Jeon, C.J. and Kim, H., Gene and microRNA expression signatures of human mesenchymal stromal cells in comparison to fibroblasts, Cell Tissue Res., 335(3).565-573, 2009.

[12] Sabatini, F., Petecchia, L., Tavian, M., Jodon de Villeroché, V., Rossi, G.A. and Brouty-Boyé, D., Human bronchial fibroblasts 
exhibit a mesenchymal stem cell phenotype and multilineage differentiating potentialities, Lab Invest. 85: 962-971, 2005.

[13] Filer, A., Parsonage, G., Smith, E., Osborne, C., Thomas, A.M., Curnow, S.J., Rainger, G.E., Raza, K., Nash, G.B., Lord, J., Salmon, M. and Buckley, C.D., Differential survival of leukocyte subsets mediated by synovial, bone marrow, and skin fibroblasts, Arthritis Rheum. 54(7): 2096-2108, 2006.

[14] Horwitz, E.M., Le Blanc, K., Dominici, M., Mueller, I., SlaperCortenbach, I., Marini, F.., Deans, R.J., Krause, D.S. and Keating, A., "Clarification of the nomenclature for MSC: The International Society for Cellular Therapy position statement," Cytotherapy. 7.393-395. 2005

[15] Haniffa, M.A., Collin, M.P., Buckley, C.D. and Dazzi, F., "Mesenchymal stem cells: the fibroblasts' new clothes?," Haematologica. 94.258-263. Feb.2009.

[16] Potian, J.A., Aviv, H., Ponzio, N.M., Harrison, J.S. and Rameshwar, P., "Veto-like activity of mesenchymal stem cells: Functional discrimination between cellular responses to alloantigens and recall antigens," J Immunol. 171.3426-3434. Oct.2003.

[17] Harris, J., "Fibroblasts and their transformations: the connectivetissue cell family," In Molecular Biology of the Cell. 3rd Edition. Edited by Alberts, B., Bra,y D., Lewis, J., Raff, M., Roberts, K. and Watson, .JD. New York: Garland Publishing; 1994:1179-1193.

[18] Takahashi, K. and Yamanaka S., "Induction of pluripotent stem cells from mouse embryonic and adult fibroblast cultures by defined factors," Cell. 126.663-676. Aug.2006.

[19] Kundig, T.M., Bachmann, M.F., DiPaolo, C., Simard, J.J., Battegay, M., Lother, H., Gessner, A., Kuhlcke, K., Ohashi, P.S., Hengartner, H. and Zinkernagel, R.M., "Fibroblasts as efficient antigen-presenting cells in lymphoid organs," Science. 268.1343 1347. Jun.1995.

[20] Korn, J.H., "Modulation of lymphocyte mitogen responses by cocultured fibroblasts," Cell Immunol. 63.374-384. Sep.1981.

[21] Suva, D., Passweg, J., Arnaudeau, S., Hoffmeyer, P. and Kindler, V., "In vitro activated human $\mathrm{T}$ lymphocytes very efficiently attach to allogenic multipotent mesenchymal stromal cells and transmigrate under them," J Cell Physiol. 214.588-594. Mar.2008.

[22] Quaedackers, M.E., Baan, C.C., Weimar, W. and Hoogduijn, M.J., "Cell contact interaction between adipose-derived stromal cells and allo-activated T lymphocytes," Eur J Immunol. 39.3436-3446. Dec.2009.

[23] Andreeva, E.R., Gornostaeva, A.N., Andrianova, I.V., Grigorieva O.G., Buravkov, S.V., Rylova, Y.V. and Buravkova, L.B. "Morphologic aspects of immune and multipotent mesenchymal stromal cells' interactions in vitro. In: Stem cells and regenerative medicine. Edited by Tkachk, V.A., Moscow: Maks-press: 2011:131-145

[24] Dexter, T.M., "Stromal cell associated haemopoiesis," J Cell Physiol. Suppl. 1.87-94. 1982.

[25] Hofmeister, C.C., Zhang, J., Knight, K.L., Le, P. and Stiff PJ., "Ex vivo expansion of umbilical cord blood stem cells for transplantation: growing knowledge from the hematopoietic niche," Bone Marrow Transplant. 39.11-23. Jan.2007.

[26] Wagner, W., Wein, F., Seckinger, A., Frankhauser, M., Wirkner, U., Krause, U., Blake, J., Schwager, C., Eckstein, V., Ansorge, W. and Ho, A.D., "Comparative characteristics of mesenchymal stem cells from human bone marrow, adipose tissue, and umbilical cord blood," Experimental Hematology. 33.1402-1416. Nov.2005.

[27] Kobari, L., Dubart, A., Le Pesteur, F., Vainchenker, W. And Sainteny, F., "Hematopoietic-promoting activity of the murine stromal cell line MS-5 is not related to the expression of the major hematopoietic cytokines," J Cell Physiol. 163.295-304. May.1995.

[28] Aoyama, K., Oritani, K., Yokota, T., Ishikawa, J., Nishiura, T., Miyake, K., Kanakura, Y., Tomiyama, Y., Kincade, P.W. "Matsuzawa Y: Stromal cell CD9 regulates differentiation of hematopoietic stem/progenitor cells," Blood. 93.2586-2594. Apr.1999.
[29] Freund, D., Bauer, N., Boxberger, S., Feldmann, S., Streller, U., Ehninger, G., Werner, C., Bornhäuser, M., Oswald, J. and Corbeil, D., "Polarization of human hematopoietic progenitors during contact with multipotent mesenchymal stromal cells: effects on proliferation and clonogenicity," Stem Cells Dev. 15.815-829. Dec.2006.

[30] Wagner, W., Roderburg, C., Wein, F., Diehlmann, A., Frankhauser, M., Schubert, R., Eckstein, V. and Ho, A.D., "Molecular and secretory profiles of human mesenchymal stromal cells and their abilities to maintain primitive hematopoietic progenitors," "Stem Cells. 25.2638-2647. Oct.2007.

[31] Arai, F. and Suda, T., "Maintenance of quiescent hematopoietic stem cells in the osteoblastic niche," Ann N Y Acad Sci. 1106.4153. Jun.2007.

[32] Walenda, T., Bork, S., Horn, P., Wein, F., Saffrich, R., Diehlmann, A., Eckstein, V., Ho, A.D. and Wagner, W., "Co-culture with mesenchymal stromal cells increases proliferation and maintenance of haematopoietic progenitor cells," J Cell Mol Med. 14.337-350. Jan.2010.

[33] Li, N., Feugier, P., Serrurrier, B., Latger-Cannard, V., Lesesve, J.F., Stoltz, J.F. and Eljaafari, A., "Human mesenchymal stem cells improve ex vivo expansion of adult human CD34+ peripheral blood progenitor cells and decrease their allostimulatory capacity," Exp Hematol. 35.507-515. Mar.2007.

[34] Sitkovsky, M. and Lukashev, D., "Regulation of immune cells by local tissue oxigen tension: HIF1alpha and adenosine receptors," Nat Rev Immunol. 5.712-721. Sep.2005.

[35] Roman, J., Rangasamy, T., Guo, J., Sugunan, S., Meednu, N., Packirisamy, G., Shimoda, L.A., Golding, A., Semenza, G. and Georas, S.N., "T-cell activation under hypoxic conditions enhances IFN-gamma secretion," Am J Respir Cell Mol Biol..42.123-128. Jan.2010

[36] Buravkova, L.B., Grigorieva, O.G., Andreeva, E.R., Andrianova, I.V. and Rylova, Y.V., "Subpopulation Composition and Activation of $\mathrm{T}$ Lymphocytes during Coculturing with Mesenchymal Stromal Cells in Medium with Different O2 Content,” Bull Exp Biol Med. 151.344-346. Jul.2011.

[37] Grinakovskaya, O.S., Andreeva, E.R., Buravkova, L.B., Rylova, Y.V, and Kosovsky, G.Y., "ow level of O2 inhibits commitment of cultured mesenchymal stromal precursor cells from the adipose tissue in response to osteogenic stimuli," Bull Exp Biol Med. 147.760-763. Jun.2009.

[38] Ma, T., Grayson, W.L., Frohlich, M. and Vunjak-Novakovic G., "Hypoxia and stem cell-based engineering of mesenchymal tissues," Biotechnol Prog. 25.32-42. Jan-Feb.2009.

[39] Cipolleschi, M.G., Dellosbarba, P. and Olivotto M., "The role of hypoxia in the maintenance of hematopoietic stem-cells," Blood. 2.2031-2037. Oct.1993.

[40] Parmar, K., Mauch, P., Vergilio, J.A., Sackstein, R. and Down, J.D., "Distribution of hematopoietic stem cells in the bone marrow according to regional hypoxia," Proc Natl Acad Sci USA. 104.5431-5436. Mar.2007.

[41] Shima, H., Takubo, K., Iwasaki, H., Yoshihara, H., Gomei, Y., Hosokawa, K., Arai, F., Takahashi, T. and Suda, T., "Reconstitution activity of hypoxic cultured human cord blood CD34-positive cells in NOG mice," Biochem Biophys Res Commun. 378.467-472. Jan.2009.

[42] Ivanovic, Z., Hermitte, F., Brunet de la Grange, P., Dazey, B., Belloc, F., Lacombe, F., Vezon, G. and Praloran, V., "Simultaneous maintenance of human cord blood SCIDrepopulating cells and expansion of committed progenitors at low O2 concentration (3\%)," Stem Cells. 2.716-724. 2004.

[43] Zhambalova, A.P., Darevskaya, A.N., Kabaeva, N.V., Romanov, Y.A., Buravkova, L.B., "Specific interaction of cultured human mesenchymal and hemopoietic stem cells under conditions of reduced oxygen content," Bull Exp Biol Med. 147.525-30. Apr.2009. 